\title{
Evaluation of the influence of aggregate type on selected properties of epoxy mortars
}

\author{
Bernardeta Dębska ${ }^{1, *}$, Katarzyna Wójcik ${ }^{1}$ \\ ${ }^{1}$ Rzeszow University of Technology, The Faculty of Civil and Environmental Engineering and \\ Architecture, Poznanska 2, 35-082 Rzeszow, Poland
}

\begin{abstract}
Aggregates, or granular materials, are currently one of the most sought-after construction materials. Natural aggregate deposits are quite common in the world, but their widespread consumption and progressive environmental degradation forces many countries to take measures to reduce the depletion of natural resources. One of the solutions is the use of alternative aggregates. The use of this type of aggregates enables further minimization of the volume of wastes and their adverse impact on the environment and the neutralisation of the remaining waste by, among others, production of artificial aggregates. Forecasts for the future assume a reduction in the production of artificial aggregates, brought about by the production of alternative aggregates from recycling. Many research centres around the world conduct research on the assessment of the effect of various aggregates on the properties of concrete and mortar. This article compares selected properties, i.e. the flexural and compressive strength and bulk density of epoxy mortars, in which the natural aggregate has been partially replaced by perlite, expanded clay and rubber waste pellets. The type of filler used differentiates the mortar characteristics recorded. The tested properties of composites indicate the possibility of their use in construction industry.
\end{abstract}

\section{Introduction}

Aggregates are granular materials that are used in building construction and linear construction (roads, etc.) to produce various kinds of concrete and mortar, and in certain earthworks (embankments, etc.). According to current standards (PN-EN), aggregates are divided according to their origin: natural, artificial and recycled. However, there are opinions that this division is ambiguous, and it is more accurate to separate a group of natural and "alternative" aggregates [1-4]. The name of natural aggregates includes all mineral aggregates from natural (gravel) deposits, both gravel aggregates (gravel and sand), as well as broken aggregates - produced from solid rocks (basalt, granite, dolomite, sandstone, limestone, etc.) subjected to mechanical treatment (crushing).

Aggregate plays a special role in resinous concrete, as it is usually about $90 \%$ by volume of the whole composite [5-7]. By combining an appropriately selected aggregate, a synthetic resin and a hardener, a material with unique properties can be obtained, i.e. good

\footnotetext{
${ }^{*}$ Corresponding author: bdebska@prz.edu.pl
} 
chemical resistance and high strength with very good sealing, excellent adhesion to other building materials and characterized by a short time needed to achieve operating efficiency. When only fine aggregates are used, the resulting composite is referred to as a polymer mortar. The aggregates usually used for the production of resin mortars are natural rocks (limestone, granite, quartz). In the literature, there are examples of research conducted on the impact of the type of natural aggregates on the properties of polymer mortars, such as workability, mechanical strength, resistance to cracking and chemical resistance.

The breakdown of "alternative" aggregates is much more extensive - it is shown in Figure 1. The literature data [1-3] was used to construct the diagram. The breakdown described in Figure 1 is due to the fact that, although natural aggregate deposits are quite commonly found on the globe, already in some countries (including Arab countries, Singapore, India, some regions of China) there is a deficit or large problems are encountered with the development of new deposits. Due to the progressive degradation of the environment many countries have taken measures to stop this process and reduce the depletion of natural resources. It seems that the re-use of waste as aggregate in concrete can give positive results, both because of the possibility of the recycling of waste and the protection of natural resources. Waste polyethylene terephthalate $[8,9]$, polyurethane $[10,11]$, rubber [12] and polystyrene $[13,14]$ are among the most intensively investigated plastic wastes that can replace natural aggregate in concrete-like building composites.

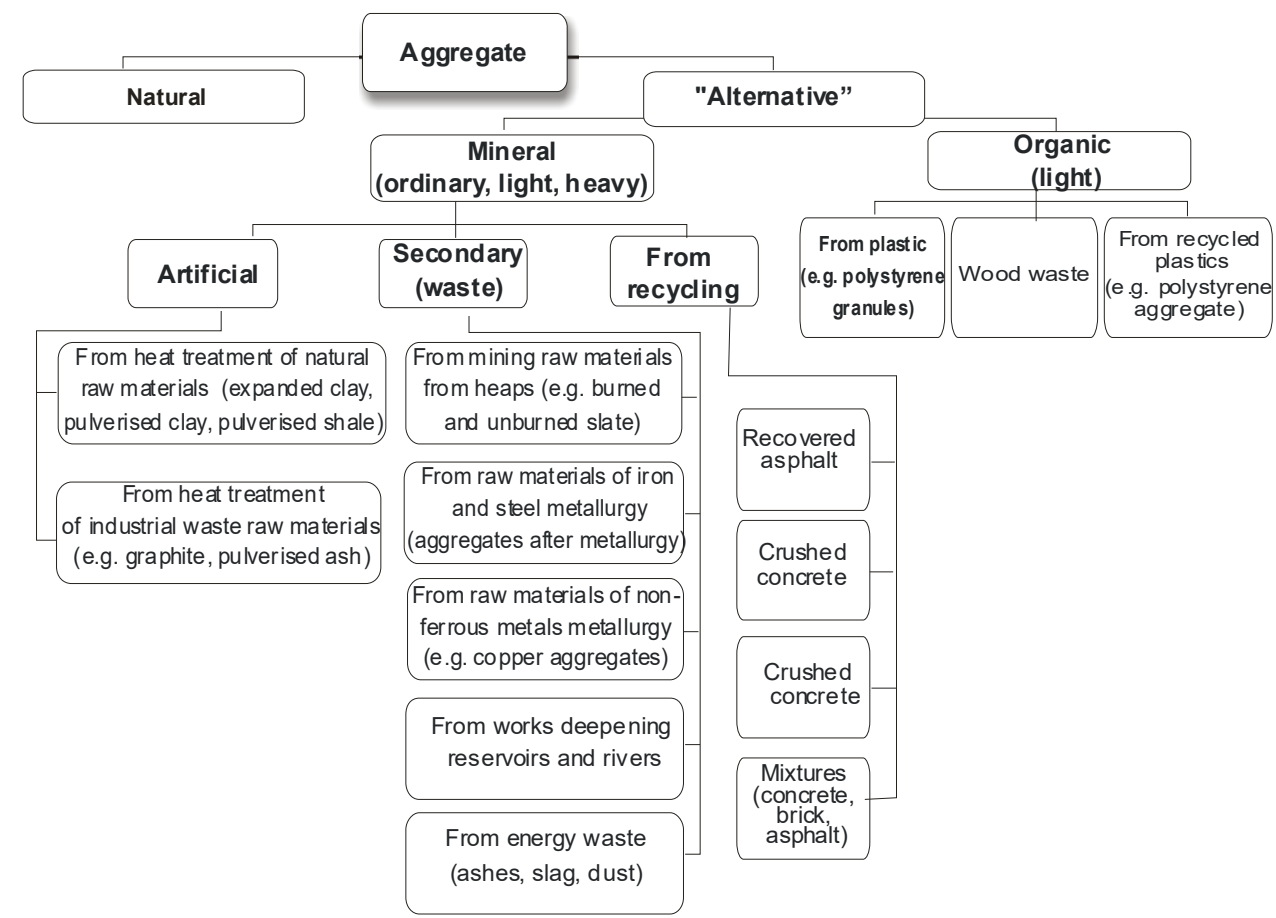

Fig. 1. Breakdown of aggregates (own elaboration based on literature data [1-3]).

Some of the research described in the literature concerns polymer mortars obtained using aggregates derived from waste, which creates an opportunity to reduce the impact factor of polymeric mortars on the environment [15-17].

This article determines the impact of selected "alternative" aggregates, i.e. perlite, expanded clay and rubber waste granulate, constituting a partial $(0-50 \%$ vol $)$ sand substitute in epoxy mortars on the strength characteristics and bulk density of the obtained composites. 


\section{Materials and Methods}

Epidian 5 epoxy resin was used to obtain the resin mortar. As the curing agent of this resin, triethylenetetramine (Z-1) was used in an amount of $10 \%$ by weight relative to the weight of the resin. The main aggregate was quartz sand of a $0-2 \mathrm{~mm}$ grain size in accordance with the PN-EN 196-1 specification. Mortar modification consisted in substituting individual sand fractions at $0,10,20,30,40$ and $50 \%$ by volume with respectively perlite $(\mathrm{P})$, expanded clay (LECA) and rubber waste granulate (RW). Bulk densities of the aggregates were for perlite $0.072 \mathrm{~g} / \mathrm{cm}^{3}$, expanded clay $-0.756 \mathrm{~g} / \mathrm{cm}^{3}$, and rubber granules $-0.486 \mathrm{~g} / \mathrm{cm}^{3}$. Photographs of the aggregates used in the research are shown in Figure 2. The determination of the grain composition was carried out in accordance with PN-EN 933-1:2000. The aggregate grain size distribution curves are summarized in Figure 3. Based on the available literature data [18] and our own research results on resin mortars [19-21], a fixed ratio of resin to aggregate of 0.22 was established.

\subsection{Sample preparation}

Adequate amounts of epoxy resin were weighed and mixed thoroughly with a hardener of $10 \%$ by weight of the resin mass until a homogeneous structure was obtained in the mixture. The resin compositions thus prepared were transferred to the bowl of a laboratory mixer and mixed with standard sand previously weighed and mixed with an appropriate amount of modifier, maintaining the same mixing time and constant rotation of the mixer. The finished mortar was placed in steel moulds with dimensions $40 \times 40 \times 160 \mathrm{~mm}$ for the purpose of strength tests and to determine the bulk density. For the curing process to take place, the samples were left for 7 days under laboratory conditions.

a)

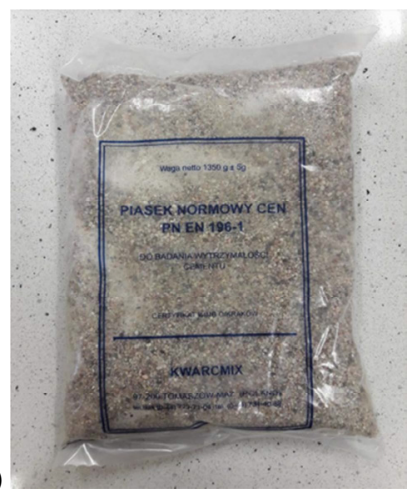

b)
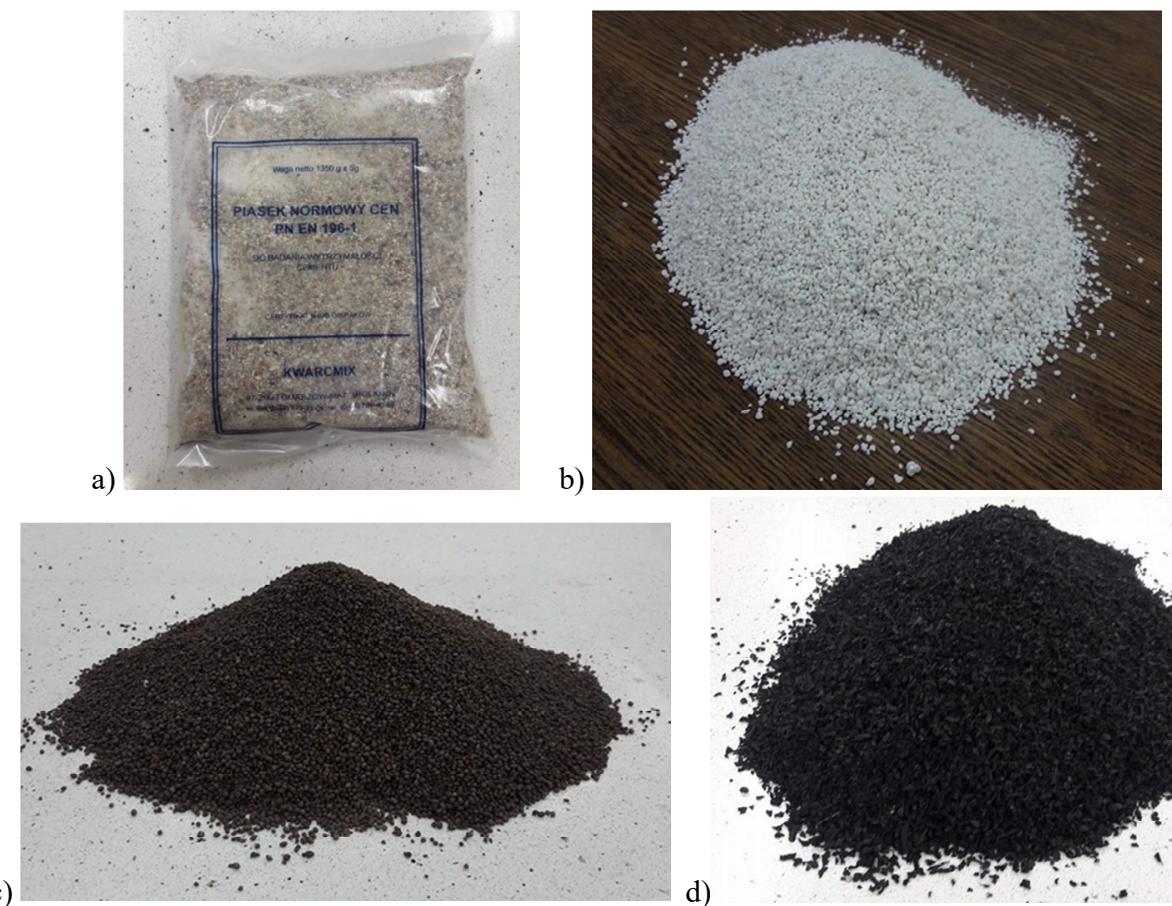

d)

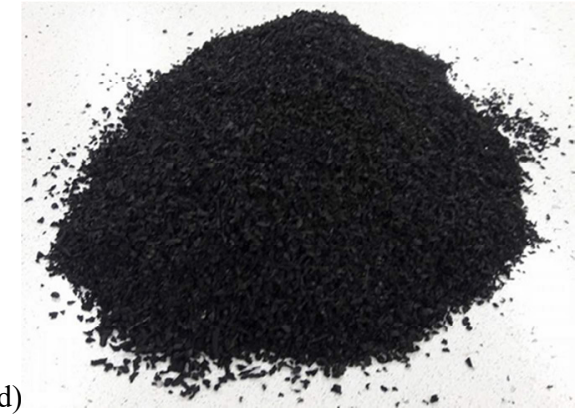

Fig. 2. Aggregates used in the preparation of mortar samples a) perlite, b) expanded clay, c) rubber waste, d) standard sand. 


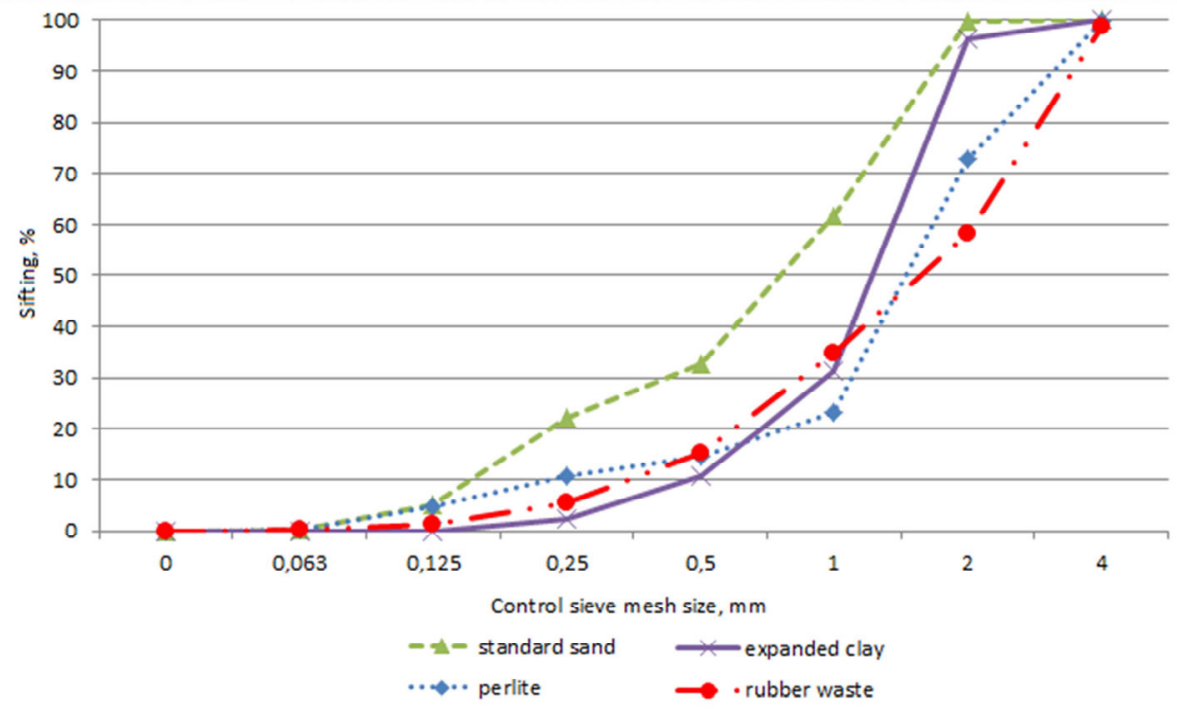

Fig. 3. Aggregate grain size distribution curves used in the study.

\subsection{Testing method}

\subsubsection{Flexural and compressive strength}

Flexural strength and compressive strength tests were carried out in strength machines equipped with appropriate inserts, in accordance with the PN-EN 196-1:2016-07 standard. For the compressive strength test, the bar halves created after the flexural strength test were used. Sample photos of breakthroughs of samples subjected to the strength test are presented in Figure 4.

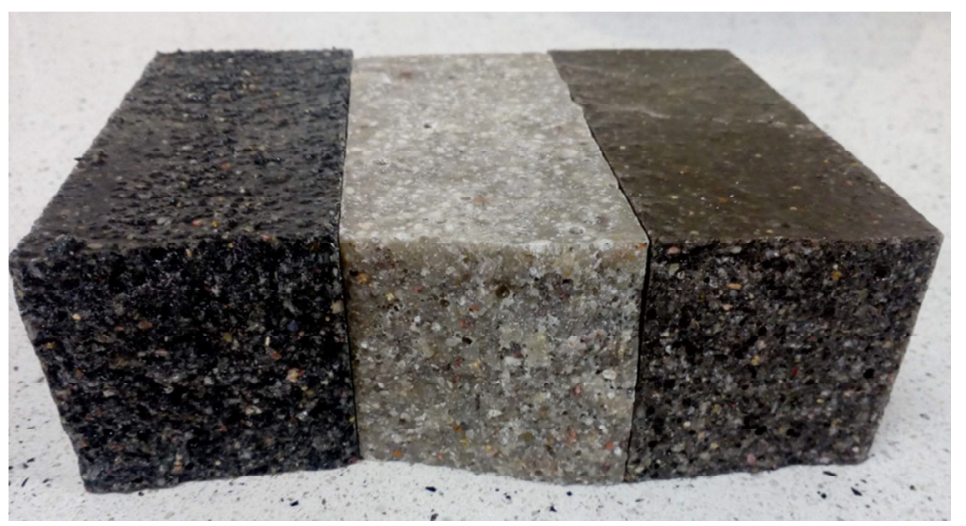

Fig. 4. Photograph of breakthroughs of mortar samples containing $50 \%$ modifier, created after the flexural strength test. 


\subsubsection{Bulk density}

Determination of bulk density was performed according to the standard PN-85/B04500:1985 for samples measuring $40 \times 40 \times 160 \mathrm{~mm}$. The weight of the bars was determined on technical scales. The volume of the samples was calculated based on their dimensions. The value of the bulk density was determined according to the equation (2):

$$
\rho=m / V
$$

where:

$\rho$ - bulk density, $\mathrm{g} / \mathrm{cm}^{3}$,

$\mathrm{m}$ - sample mass, $\mathrm{g}$,

$\mathrm{V}$ - sample volume, $\mathrm{cm}^{3}$.

\section{Results and Discussion}

After the tests, the results obtained were recorded in a STATISTICA worksheet. Data analysis began with the calculation of basic statistical measures. The average values and the measure of dispersion were determined for the designated parameters. Mean values and standard deviation of bulk density as well as flexural and compressive strengths for mortars containing perlite, expanded clay and rubber waste, are presented in tables 1-3.

Table 1. Comparison of mean values and standard deviation of results obtained during the bulk density test.

\begin{tabular}{|c|c|c|c|}
\hline \multirow{2}{*}{$\begin{array}{c}\text { Amount of alternative } \\
\text { aggregate added, } \\
\text { \% vol. }\end{array}$} & \multicolumn{3}{|c|}{ Bulk density \pm standard deviation, $\mathbf{g} / \mathbf{c m}^{\mathbf{3}}$} \\
\cline { 2 - 4 } & perlite (P) & $\begin{array}{c}\text { expanded } \\
\text { clay (LECA) }\end{array}$ & $\begin{array}{c}\text { rubber waste } \\
\text { (RW) }\end{array}$ \\
\hline 0 & $2.04 \pm 0.007$ & $2.04 \pm 0.007$ & $2.04 \pm 0.007$ \\
\hline 10 & $2.01 \pm 0.024$ & $2.01 \pm 0.021$ & $1.98 \pm 0.006$ \\
\hline 20 & $1.89 \pm 0.026$ & $1.94 \pm 0.008$ & $1.89 \pm 0.019$ \\
\hline 30 & $1.86 \pm 0.012$ & $1.86 \pm 0.009$ & $1.82 \pm 0.008$ \\
\hline 40 & $1.81 \pm 0.007$ & $1.81 \pm 0.005$ & $1.75 \pm 0.011$ \\
\hline 50 & $1.75 \pm 0.005$ & $1.75 \pm 0.009$ & $1.67 \pm 0.015$ \\
\hline
\end{tabular}

Table 2. Comparison of mean values and standard deviation of results obtained during the flexural strength test.

\begin{tabular}{|c|c|c|c|}
\hline \multirow{2}{*}{$\begin{array}{c}\text { Amount of alternative } \\
\text { aggregate added, } \\
\text { \% vol. }\end{array}$} & \multicolumn{3}{|c|}{ Flexural strength \pm standard deviation, MPa } \\
\cline { 2 - 4 } & perlite (P) & $\begin{array}{c}\text { expanded } \\
\text { clay (LECA) }\end{array}$ & $\begin{array}{c}\text { rubber waste } \\
\text { (RW) }\end{array}$ \\
\hline 0 & $28.36 \pm 0.89$ & $28.36 \pm 0.89$ & $28.36 \pm 0.89$ \\
\hline 10 & $26.49 \pm 0.53$ & $27.51 \pm 0.55$ & $21.75 \pm 1.84$ \\
\hline 20 & $25.66 \pm 0.38$ & $26.91 \pm 0.38$ & $18.35 \pm 2.83$ \\
\hline 30 & $24.67 \pm 0.06$ & $26.09 \pm 0.67$ & $16.19 \pm 1.04$ \\
\hline 40 & $23.49 \pm 0.57$ & $25.48 \pm 0.88$ & $16.28 \pm 0.33$ \\
\hline 50 & $23.35 \pm 0.15$ & $24.66 \pm 0.55$ & $13.01 \pm 0.63$ \\
\hline
\end{tabular}


Table 3. Comparison of mean values and standard deviation of results obtained during the compressive strength test.

\begin{tabular}{|c|c|c|c|}
\hline \multirow{2}{*}{$\begin{array}{c}\text { Amount of alternative } \\
\text { aggregate added, } \\
\text { \% vol. }\end{array}$} & \multicolumn{3}{|c|}{$\begin{array}{c}\text { Compressive strength } \pm \text { standard deviation, } \\
\text { MPa }\end{array}$} \\
\cline { 2 - 4 } & perlite (P) & $\begin{array}{c}\text { expanded } \\
\text { clay (LECA) }\end{array}$ & $\begin{array}{c}\text { rubber waste } \\
\text { (RW) }\end{array}$ \\
\hline 0 & $103.45 \pm 5.24$ & $103.45 \pm 5.24$ & $103.45 \pm 5.24$ \\
\hline 10 & $105.30 \pm 4.34$ & $104.10 \pm 3.67$ & $88.42 \pm 1.67$ \\
\hline 20 & $101.60 \pm 1.96$ & $100.53 \pm 1.45$ & $75.52 \pm 0.99$ \\
\hline 30 & $96.62 \pm 2.46$ & $96.38 \pm 1.15$ & $63.23 \pm 3.25$ \\
\hline 40 & $91.87 \pm 0.38$ & $86.43 \pm 1.74$ & $53.93 \pm 1.21$ \\
\hline 50 & $88.53 \pm 0.81$ & $78.87 \pm 1.11$ & $44.83 \pm 1.06$ \\
\hline
\end{tabular}

With increasing addition of the alternative aggregate, the values of all of the recorded parameters decrease. The nature of the changes could be assessed by presenting the results in a graphical form and then determining the equations of the regression curve. Using the Scatter Charts module available in the STATISTICA program, the equations of functions, shown in Figures 5-8, were adjusted to the empirical data. A visual assessment of the distribution of measuring points in the diagrams suggests that the results of the flexural strength and compressive strength tests can fit a linear approximation model function, of the general formula (1):

$$
y=a+b \cdot x
$$

In the case of bulk density and both tested strengths, this model well describes the empirical data, as evidenced by, among others, the high values of $\mathrm{R}^{2}$ coefficients, ranging from 0.7531 to 0.9932 . The resulting $\mathrm{R}^{2}$ coefficients of determination and the calculated function coefficients are summarized in Table 4.

The bulk density of epoxy mortars containing perlite, expanded clay and rubber waste decreases with increasing modifier content (Fig. 5). The bulk density decreased from the value of $2.04 \mathrm{~g} / \mathrm{cm}^{3}$, in the case of samples containing only quartz sand as the aggregate, to the value of about $1.75 \mathrm{~g} / \mathrm{cm}^{3}$ for mortars with $50 \%$ content of perlite and expanded clay. The lines for these two types of aggregates are practically overlapping each other. The addition of rubber waste resulted in significantly greater reduction in bulk density of mortars. With $50 \%$ substitution of sand with this waste, the parameter determined decreased to $1.67 \mathrm{~g} / \mathrm{cm}^{3}$. The resulting composite is lighter in comparison with cement concrete (bulk density equal to approx. $2.4 \mathrm{~g} / \mathrm{cm}^{3}$ ) by approx. $30 \%$. Reducing the weight of the composite is of great importance due to the possibility of its application, for example to obtain prefabricated elements used, among others, in road and bridge drainage systems.

Table 4. Parameters of the regression line and determination coefficients for various types of aggregates.

\begin{tabular}{|c|c|c|c|c|}
\hline Recorded parameter type & $\begin{array}{c}\text { Type of alternative } \\
\text { aggregate added }\end{array}$ & $\mathbf{a}$ & $\mathbf{b}$ & $\mathbf{R}^{\mathbf{2}}$ \\
\hline \multirow{3}{*}{ Bulk density } & $\mathrm{P}$ & 2.0403 & -0.0059 & 0.9620 \\
\cline { 2 - 5 } & $\mathrm{LECA}$ & 2.0514 & -0.0061 & 0.9843 \\
\cline { 2 - 5 } & $\mathrm{RW}$ & 2.0447 & -0.0075 & 0.9932 \\
\hline \multirow{3}{*}{ Flexural strength } & $\mathrm{P}$ & 27.8394 & -0.1002 & 0.9034 \\
\cline { 2 - 5 } & $\mathrm{LECA}$ & 28.5730 & -0.0796 & 0.8777 \\
\cline { 2 - 5 } & $\mathrm{RW}$ & 25.7981 & -0.2724 & 0.8324 \\
\hline \multirow{3}{*}{ Compressive strength } & $\mathrm{P}$ & 106.4563 & -0.3425 & 0.7531 \\
\cline { 2 - 5 } & $\mathrm{LECA}$ & 107.823 & -0.5145 & 0.8258 \\
\cline { 2 - 5 } & $\mathrm{RW}$ & 100.7651 & -1.1680 & 0.9753 \\
\hline
\end{tabular}


Graphs of the dependence of flexural and compressive strengths on the percentage of, respectively, perlite, expanded clay and rubber waste in the composite are presented in Figures 6-8.

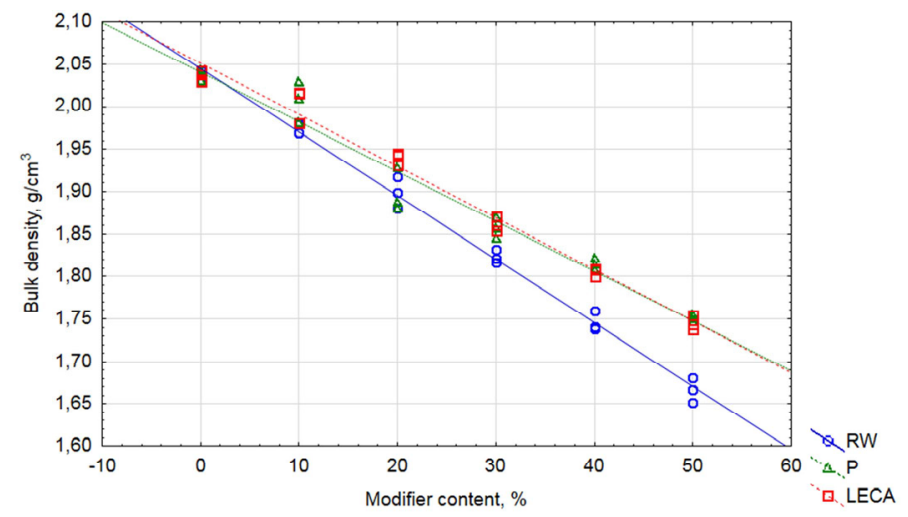

Fig. 5. Dependence of bulk density on the percentage of particular types of aggregates.

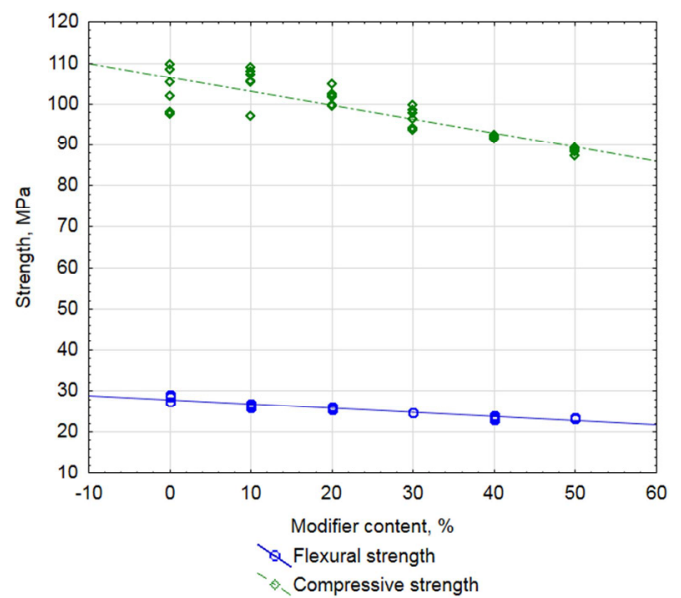

Fig. 6. Graphs of functions describing the dependence of flexural and compressive strengths on the percentage of perlite in the mortar.

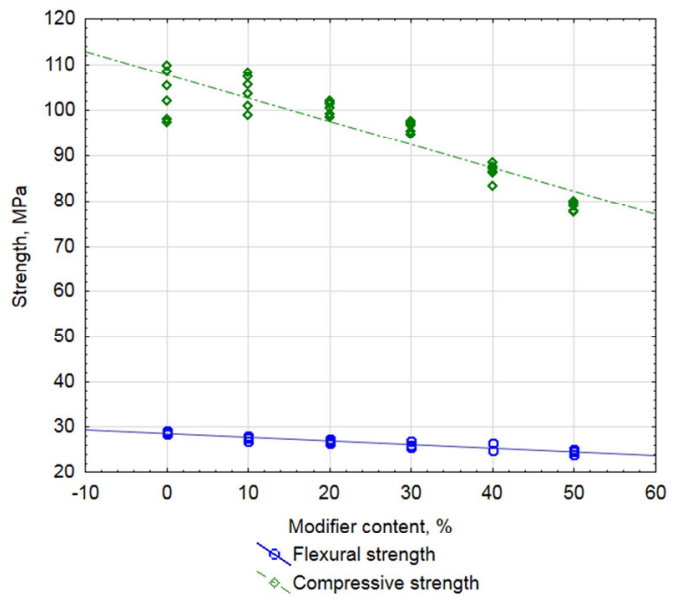

Fig. 7. Graphs of functions describing the dependence of flexural and compressive strengths on the percentage of expanded clay in mortar. 


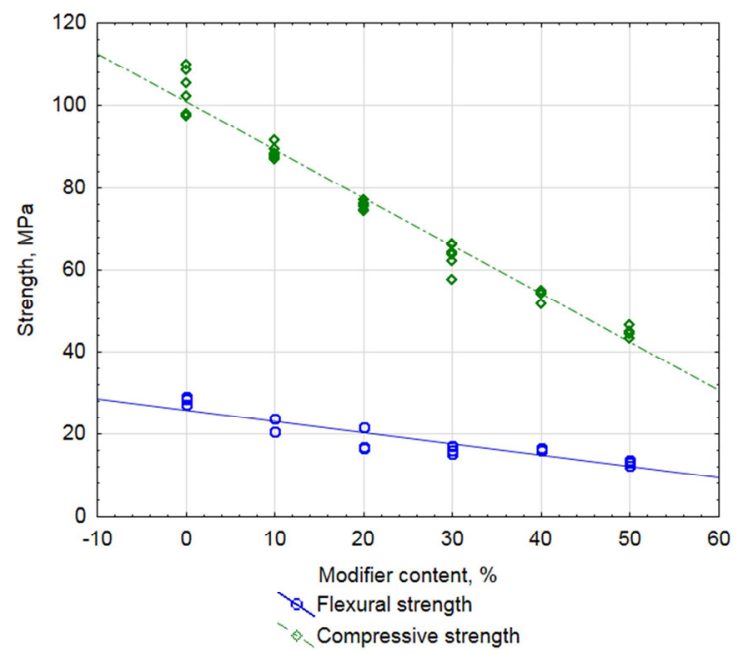

Fig. 8. Graphs of functions describing the dependence of flexural and compressive strengths on the percentage of rubber waste in mortar.

Both the flexural strength and compressive strength decrease with an increase in the content of alternative aggregate. The lowest values of the parameters determined were noted at $50 \%$ substitution of sand by a given type of aggregate. The average flexural strength values were $23.35 \mathrm{MPa}, 24.66 \mathrm{MPa}$ and $13.01 \mathrm{MPa}$, respectively for mortars with perlite, expanded clay and rubber granulate. The largest decrease in this strength, amounting to over $54 \%$, was therefore noted for rubber granulate. However, the presence of rubber particles in the composite meant that even after completing the flexural strength test, the sample was difficult to break completely. This fact may indicate a positive effect of rubber on the brittleness of the composite. In the future, it would be worth investigating the resistance of this kind of mortar to brittle fracturing.

Compared with samples obtained exclusively using sand, compressive strength decreased by $14.42 \%, 23.76 \%$ and $56.67 \%$, respectively for mortars containing perlite, expanded clay and rubber waste at $50 \%$ substitution of sand. The worst strength parameters were obtained in the case of substitution of sand by rubber waste pellets. The decrease in strength of mortars containing perlite and expanded clay is also important, but the values of this parameter still remain at very high levels. Even the $50 \%$ substitution of sand by alternative aggregates does not discredit resin composites in the area of their application. The resulting epoxy mortar has a flexural strength at a level of 24-13 MPa and a compressive strength in the range 88-44 MPa. These parameters are higher or comparable to strength characteristics attributed to cement concretes, for which flexural strength was assumed at the level of 1.1-7.2 MPa, and compressive strength 15-60 MPa [5]. The resin composite of the same strength containing alternative aggregate is lighter than traditional concrete by approx. $30 \%$. It is ideally suited for modernization and renovation of sewerage and plumbing channels of various shapes. Thanks to the parameters characterizing resin composites, building elements can be constructed with a significantly lower wall thickness compared to traditional concrete.

\section{Conclusions}

Alternative aggregates are part of the main assumptions of rational waste management, the main purpose of which is, among others, minimization of the amount of waste and its adverse impact on the natural environment, recovery in accordance with the principles of 
environmental protection, disposal of other waste (including production of artificial aggregates). Forecasts for the future assume a reduction in the production of artificial aggregates, brought about by production of alternative aggregates from recycling. The research described in this article leads to the following conclusions:

- The addition of an alternative aggregate caused a reduction in the bulk density of the composite. Composites containing 50\% filler exhibit the lowest bulk density. Taking into account the type of filler, mortar with the addition of rubber granulate is characterized by the smallest bulk density, amounting to $1.67 \mathrm{~g} / \mathrm{cm}^{3}$. In the case of the other two fillers the difference is not so significant.

- Substitution of aggregates in epoxy mortars results in lowering of the strength parameters; however, even $50 \%$ replacement of sand allows us to obtain a composite that can compete with cement mortars.

- The values of the parameters determined for the mortar containing the rubber waste granulate are clearly lower compared to mortars with the addition of perlite and expanded clay. The composite obtained on the basis of rubber waste is less durable, but also lighter and more flexible, and therefore less susceptible to mechanical damage.

\section{References}

1. W. Kozioł, A. Ciepliński, Ł. Machniak, A. Borcz, Nowoczesne Budownictwo Inżynieryjne (Modern Engineering Construction), 4, 98-100 (2015)

2. W. Kozioł, A. Ciepliński, Ł. Machniak, A. Borcz, Nowoczesne Budownictwo Inżynieryjne (Modern Engineering Construction), 5, 35-38 (2015)

3. S. Góralczyk, D. Kuklelska, Kruszywa wtórne (Secondary aggregates), 33-38 (2011)

4. I. Baic, W. Kozioł, Ł. Machniak, E3S Web of Conferences 8, 01068 (2016)

5. L. Czarnecki, Cem. Lime Concrete 2, 63-85 (2010)

6. B. Dębska, L. Lichołai, Period. Polytech. Civ. Eng. 60, 281-287 (2016)

7. B. Dębska, L. Lichołai, Constr. Build. Mater. 124, 11-19 (2016)

8. N. Saikia, J. de Brito, Constr. Build. Mater. 34, 385-401 (2012)

9. B. W. Jo, S. K. Park, J. Ch. Park, Constr. Build. Mater. 22 2281-2291 (2008)

10. A. B. Fraj, M. Kismi, P. Mounanga, Constr. Build. Mater. 24 1069-77 (2010)

11. P. Mounanga, W. Gbongbon, P. Poullain, P. Turcry, Cem. Concr. Compos. 30 806-814 (2008)

12. V. Corinaldesi, A. Mazzoli, G. Moriconi, Mater. Des. 32 1646-1650 (2011)

13. Z.Z. Ismail, E. A. Al-Hashmi, Waste Manage. 28 2041-2047 (2008)

14. B. Dębska, L. Lichołai, JCEEA, 63 (4/16), 87-96 (2016)

15. M. Muthukumar, D. Mohan, Eur. Polym. J. 40, 2167-2177 (2004)

16. A. Bourguiba, E. Ghorbel, L. Cristofol, W. Dhaoui, Constr. Build. Mater. 153, 44-54 (2017)

17. B. Dębska, L. Lichołai, P. Godek, J. Ecol. Eng. 17, 72-78 (2016)

18. J.M.L. Reis, E.P. Carneiro, Constr. Build. Mater. 27, 107-111 (2012)

19. B. Dębska, L. Lichołai, J. Ecol. Eng. 19, 204-212 (2018)

20. B. Dębska, Poly(ethylene Terephthalate) Based Blends, Composites and Nanocomposites( in: P.M. Visakh, M. Liang (Eds.) Reed Elsevier Inc., 195-212, 2015)

21. L. Lichołai, B. Dębska, Arch. Civil Mech. Eng. 14, 466-475 (2014) 